\title{
Experiência Brasileira na Formação de Professores Ibero- Americanos em Tecnologias Digitais Acessíveis
}

\author{
Lucila Santarosa, Débora Conforto \\ Núcleo de Informática na Educação Especial (NIEE) \\ Universidade Federal do Rio Grande do Sul (UFRGS) \\ Porto Alegre - RS - Brazil \\ \{lucila.santarosa.ufrgs.br, deboraconforto@gmail.com\}
}

\begin{abstract}
Abstratc: This article presents the experience of teacher training courses on Accessible Digital Technologies in Latin American countries, an action of the Brazilian government, designed and managed by the Ministry of Education (MEC). The course started in 2009, and educators from different Spanish-speaking countries have benefited from the Brazilian experience in teacher training for the socio-digital inclusion of people with disabilities. When we share this successful international partnership, a productive theoretical and practical trajectory in the area of digital technologies, we intend to promote the emergence of new international training and research partnerships in order to foster the socio-digital inclusion of human diversity.
\end{abstract}

Resumo: Este artigo apresenta a experiência de formação de professores de países ibero-americanos em Tecnologias Digitais Acessíveis, uma ação do governo brasileiro, projetada e gerenciada pelo Ministério da Educação (MEC). Iniciado em 2009, educadores de diferentes países de língua espanhola têm se beneficiado da experiência brasileira de formação de educadores para a inclusão sociodigital de pessoas com deficiência. Ao socializarmos essa exitosa parceira internacional, uma produtiva trajetória teórica-prática na área das tecnologias digitais, objetivamos a emergência de novas parceiras internacionais, de formação e de pesquisa para impulsionar a inserção sociodigital da diversidade humana.

\section{Introdução}

O conhecimento da Informática aplicada à Educação Especial, a implementação e validação de ferramentas e de ambientes digitais/virtuais de aprendizagem acessíveis, a formação de recursos humanos no âmbito da Informática na Educação Especial, antes mesmo que a Educação Inclusiva passasse a estruturar processos de escolarização, atestam a credibilidade da equipe do Núcleo de Informática na Educação Especial (NIEE), da Universidade Federal do Rio Grande do Sul (UFRGS), para assumir a responsabilidade da formação de docentes visando a inclusão escolar para sujeitos marcados pelo rótulo da incapacidade e, por isso, colocados na exterioridade processos de socioculturais. 
O NIEE é uma referência nacional e internacional no campo de saber da Informática na Educação Especial, com mais de 30 anos de investigação, formação e desenvolvimento de tecnologias no campo de saber da Educação Especial. Sua equipe é constituída por pesquisadores e professores universitários, alunos dos cursos de PósGraduação em Educação e de Informática na Educação, de diferentes áreas de conhecimento. Um pouco da trajetória do NIEE/UFRGS pode ser conhecida por meio dos três principais campos de pesquisa, eixos que atuam em complementaridade, alimentados por inúmeras investigações de especialização, mestrado e doutorado no âmbito da Informática na Educação Especial:

\section{Eixo - Investigação e Desenvolvimento Tecnológico}

Eixo que assume como escopo o desenvolvimento e validação de tecnologias digitais acessíveis, implementadas em software livre para impulsionar o processo de inclusão sociodigital de pessoas com deficiências.

\section{Eixo - Investigações de processos de inclusão sociodigital para pessoas com deficiência}

Eixo de pesquisa que objetiva mapear os movimentos de inclusão sociodigital junto à diversidade humana. Pesquisas financiadas pelo CNPq. [Santarosa, 2009]

\section{Eixo: Formação de Professores em Tecnologias Digitais Acessíveis}

Eixo que assume como escopo a formação de professores em atuação nas redes públicas de ensino, no âmbito das tecnologias digitais acessíveis, para concretizar a configuração do processo educativo brasileiro na perspectiva da Educação Inclusiva [Santarosa et al, 2010].

A solidez da contribuição científica e metodológica do NIEE/UFRGS impulsiona seus pesquisadores a desenhar um processo de formação de educadores brasileiros e ibero-americanos, objetivando mediar processos de aprendizagem e de desenvolvimento para alunos com deficiência. A relevância deste eixo de atuação é inegável, uma vez que a inclusão sociodigital da diversidade humana assume contemporaneamente sua importância, fazendo-se presente em ações do governo em diferentes pastas ministeriais. Sob o desafio dessa última ação proposta que a formação em Tecnologias Digitais Acessíveis vem dialogando com os educadores brasileiros e ibero-americanos.

\section{Formação de educadores ibero-americanos para a diversidade humana}

A Educação Inclusiva emerge em um contexto de social de intensas e dinâmicas transformações provocadas pelo acirramento dos processos de globalização e pelo acelerado desenvolvimento tecnológico. A conquista da fluência digital pela significativa parcela da população com algum tipo de deficiência passa a ser uma das metas assumidas pela sociedade, pois a não apropriação das funcionalidades das tecnologias digitais pode potencializar o estado de vulnerabilidade social e ampliar as dificuldades de acesso à educação e de ingresso no mundo do trabalho.

Vivenciando os ideais de justiça e equidade social, a Rede de Formação Continuada de Professores, da Secretaria de Educação Continuada, Alfabetização, Diversidade e Inclusão (SECADI/MEC), vem gerenciando e financiando cursos de 
extensão e de especialização, na modalidade a distância, visando a capacitação de professores na perspectiva da Educação Inclusiva. Para responder ao desafio da formação docente no âmbito das tecnologias digitais, e compondo a rede de formação continuada projetada pela SECADI/MEC, a UFRGS vem desenvolvendo, ao longo dos últimos dez anos, o curso de Formação de Professores em Tecnologias de Informação e Comunicação Acessíveis com os objetivos de: (1) formar em serviço, na modalidade a distância, via Internet, professores para a apropriação e aplicação pedagógica das Tecnologias da Informação e da Comunicação com vistas à inclusão de alunos com deficiência; (2) experienciar, projetar e desenvolver ações pedagógicas significativas, mediadas pelas tecnologias digitais de informação e de comunicação e pelos recursos de acessibilidade alicerçados na premissa da inclusão sociodigital de sujeitos com deficiência no cenário sociocultural contemporâneo.

O curso de Formação de Professores em Tecnologias de Informação e Comunicação Acessíveis, desenvolvido na modalidade a distância, utiliza as ferramentas de mediação e de comunicação disponibilizadas em ambiente virtual de aprendizagem. Por meio de uma metodologia de ensino ajustada à modalidade da Educação a Distância (EAD), o curso supõe o desenvolvimento de estratégias de aprendizagem e a publicação na plataforma virtual das atividades previstas para cada componente da base curricular, por meio de uma sequência de fases: (1) Fase Sensibilização: apresentação e sensibilização às temáticas em foco através de conferências pela internet e de ferramentas de comunicação síncrona (chat) e assíncrona (mensagens eletrônicas, fóruns...); (2) Fase Imersão: vinculação ao contexto da escola, diagnosticando a realidade escolar e trazendo casos existentes para a proposição das possíveis formas de intervenção; (3) Fase Problematização: apropriação conceitual por meio de interações síncronas e assíncronas; (4) Fase Consolidação: construção e reconstrução conceitual, socializando os resultados edificados ao longo do processo de aprendizagem individual e coletiva.

A opção metodológica do curso centra-se na interação de seus participantes professores, formadores, tutores, coordenadores - para edificar uma verdadeira comunidade virtual de aprendizagem. Nessa perspectiva, dois níveis da formação docente em serviço são contemplados: (1) Nível 1 - Apropriação técnicometodológica: o educador em formação, pela constante e qualificada interação com a equipe técnico-pedagógica do curso e, por meio de sua participação nos fóruns, chats, conferências, via internet, articulará o domínio tecnológico com a prática pedagógica, mediada por diferentes linguagens e ferramentas; (2) Nível 2 - Aplicação na unidade educativa: o professor, em seu contexto de docência, modelará estratégias de intervenção pela interface das tecnologias digitais, de forma pontual, experienciando possibilidades de qualificação de práticas pedagógicas com as linguagens e ferramentas digitais desenvolvidas ao longo do curso, além de estabelecer um efetivo apoio na construção do plano de intervenção para sujeitos com deficiência.

O curso tem a duração de 180 horas, contemplando diferentes aspectos técnicometodológicos relacionados às tecnologias digitais inclusivas (Figura 1). Organizado em seis módulos, sua estrutura curricular apresenta como fio condutor o campo de saber das Tecnologias Assistivas:

Módulo I - Tecnologias de Informação e de Comunicação Acessíveis e Política Nacional de Educação Especial - Contextualiza as Tecnologias de Informação e de Comunicação na perspectiva da Educação Inclusiva. Explora e instrumentaliza professores para as possibilidades técnico-metodológicas em um curso de formação na modalidade não presencial. Reflete sobre as políticas 
públicas, impulsionando a modelagem de planos de intervenção sociocognitiva, com vistas à inclusão escolar qualificada.

Módulo II - Introdução à Informática Acessível - Define e caracteriza Tecnologia Assistiva. Explorar, observar e manusear diferentes dispositivos e interfaces de hardware e software que possibilitem o acesso aos recursos de ambientes computacionais para a diversidade humana. Construção do aporte técnico e metodológico para a utilização de alta tecnologia para a inclusão escolar.

Módulo III - Recursos de Internet Acessíveis - Explora e reflete sobre os usos pedagógicos da Internet - navegação, comunicação e produção de conteúdo para Web - na perspectiva da Educação Inclusiva. Estuda as possibilidades educativas da Internet acessível, consorciadas à Tecnologia Assistiva.

Módulo IV - Acessibilidade à Web - Estuda critérios e requisitos de promoção do acesso à Web para a diversidade humana. Observa e utiliza sistemas de avaliação e validação de conteúdo para a Web, consorciado à Tecnologia Assistiva.

Módulo V - Objetos de Aprendizagem Acessíveis - Conceitua dimensões teóricas e metodológicas para a utilização de objetos de aprendizagem no contexto educacional. Analisa, avalia e explora objetos de aprendizagem, consorciados à Tecnologia Assistiva, para operar como instrumentos cognitivos que levem à inclusão escolar.

Módulo VI - Estudo de Caso e Plano de Ação Pedagógica - Explora a metodologia de projetos. Identifica, analisa casos de inclusão. Estrutura e aplica o plano de intervenção para a inserção qualificada de sujeitos com necessidades especiais no processo de escolarização.

FORMACIÓN CONTINUADA DE PROFESORES EN TECNOLOGIAS DE INFORMACIÓN Y COMUNICACIÓN ACCESIBLES

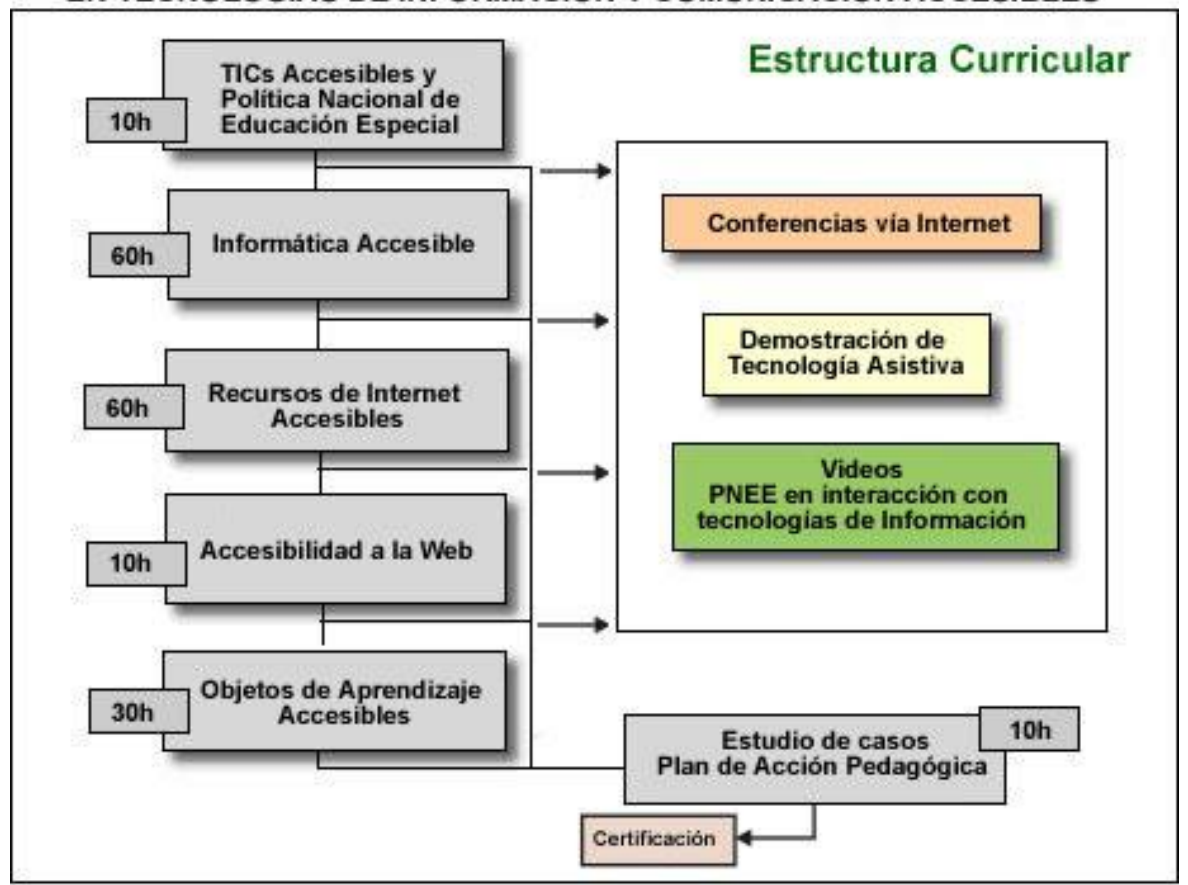

Figura 1. Estrutura curricular 
Para os módulos que compõem a estrutura curricular são oferecidos textos e matérias de apoio, tendo em mente a construção conceitual proposta em cada uma das etapas do curso. Além disso, várias conferências de renomados especialistas são apresentadas, via internet, com o fim de sensibilizar e promover a aproximação entre o professor e as temáticas que subsidiam e apoiam o processo de inclusão para alunos com deficiências na Educação Básica. Paralelamente, também são disponibilizados vídeos, inseridos nos módulos do curso, com demonstração de recursos de tecnologias assistivas e com registros de experiências de uso das tecnologias digitais em contexto escolar, que possibilitam a efetiva participação de sujeitos com deficiência e ilustram a viabilidade de práticas de inclusão sociodigital.

O governo brasileiro, por meio do Ministério de Educação (MEC), oferece, gratuitamente, a formação de docentes de países de língua espanhola que desejam fazer essa capacitação, certificada pela U. A plataforma virtual do curso é configurada para a versão em espanhol, e as agendas, as atividades e o material de apoio que orientam a realização do curso são vertidos para o espanhol. As interações são mediadas por formadores e tutores que dominam a língua espanhola. A partir de 2011, os professores-cursistas têm acesso ao livro, na versão em espanhol, Tecnologías Digitales Accesibles [Santarosa, L. et al, 2011], beneficiando educadores de países iberoamericanos como Argentina, Uruguai, Chile, Colômbia, Panamá, Costa Rica, México, El Salvador e Espanha (Gráfico 1).

\section{Gráfico 1. Percentual por país de alunos de língua espanhola no Curso em Tecnologias Digitais Acessíveis}

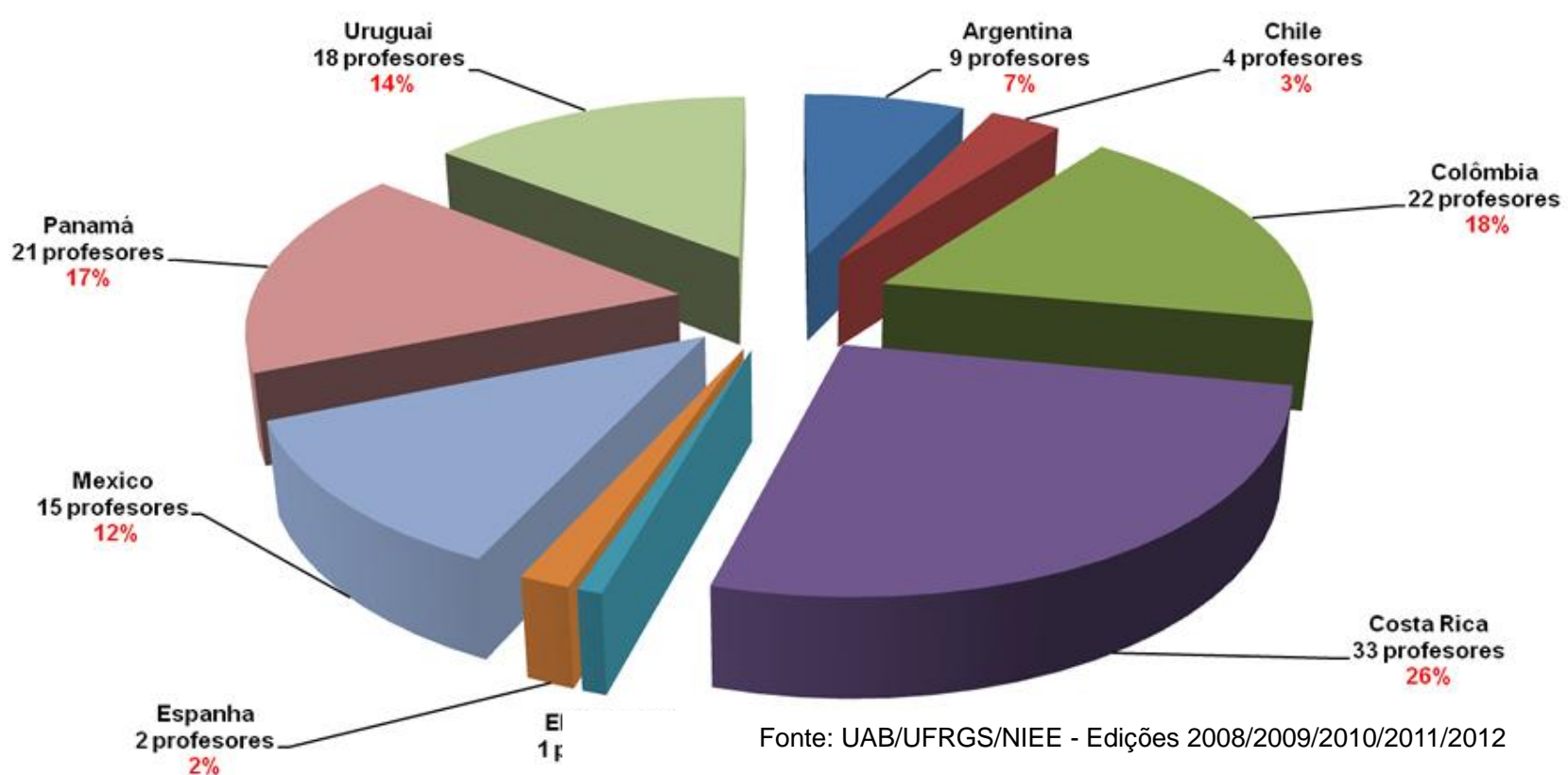

\section{As produções e as palavras dos principais atores: os professores ibero- americanos em formação}

A formação continuada de professores em Tecnologias Digitais Acessíveis, pelo representativo número de edições - em 2012 ultrapassou a $15^{a}$ edição do curso -, revela uma narrativa escrita por múltiplas mãos, tecida nas inúmeras atualizações e 
reconfigurações, ilustrada pela palavra e pela atuação dos educadores e da equipe de coordenadores que passaram por esse tempo e espaço de qualificação docente. Ao revisitar a história da formação de milhares de educadores brasileiros e, desde 2009, com o acréscimo de mais de uma centena de professores ibero-americanos, constatamos que a equipe de coordenação pedagógica e que o conjunto de formadores e de tutores, autores e atores dos princípios que estruturaram esse curso de formação, revelam-se um grupo fortalecido pelas respostas positivas da comunidade e dos alunos com deficiência nos diferentes cenários educacionais, espalhados pelo Brasil e pelos países iberoamericanos.

Por meio da atuação/intervenção de cada educador em sua instituição educativa, o diálogo teoria e prática tecido no âmbito da Informática na Educação Especial efetiva-se, desencadeando um processo sempre construído e conduzido no entrelaçamento e complementaridade da tríade explorar-aplicar-refletir. Assim, de forma direta ou indireta, esse coletivo inteligente de educadores tem espraiado vivências, demonstrado que uma trajetória de formação que tem edificado promissoras ações inclusivas por meio da interface das tecnologias digitais acessíveis.

A riqueza das produções dos educadores ibero-americanos é revelada nos diferentes módulos dos cursos. Explorando-se práticas de letramento digital: construindo blogs e glogs que abordam a temática da inclusão sociodigital em seus países; revelando sua criatividade na construção de avatares e na produção de áudio e vídeo-livros; explicitando práticas pedagógicas inclusivas pela interfaces de sites e softwares educacionais: uma multiplicidade da ações pedagógicas produzidas por professores que atestam a conquista da fluência digital (Figura 2).
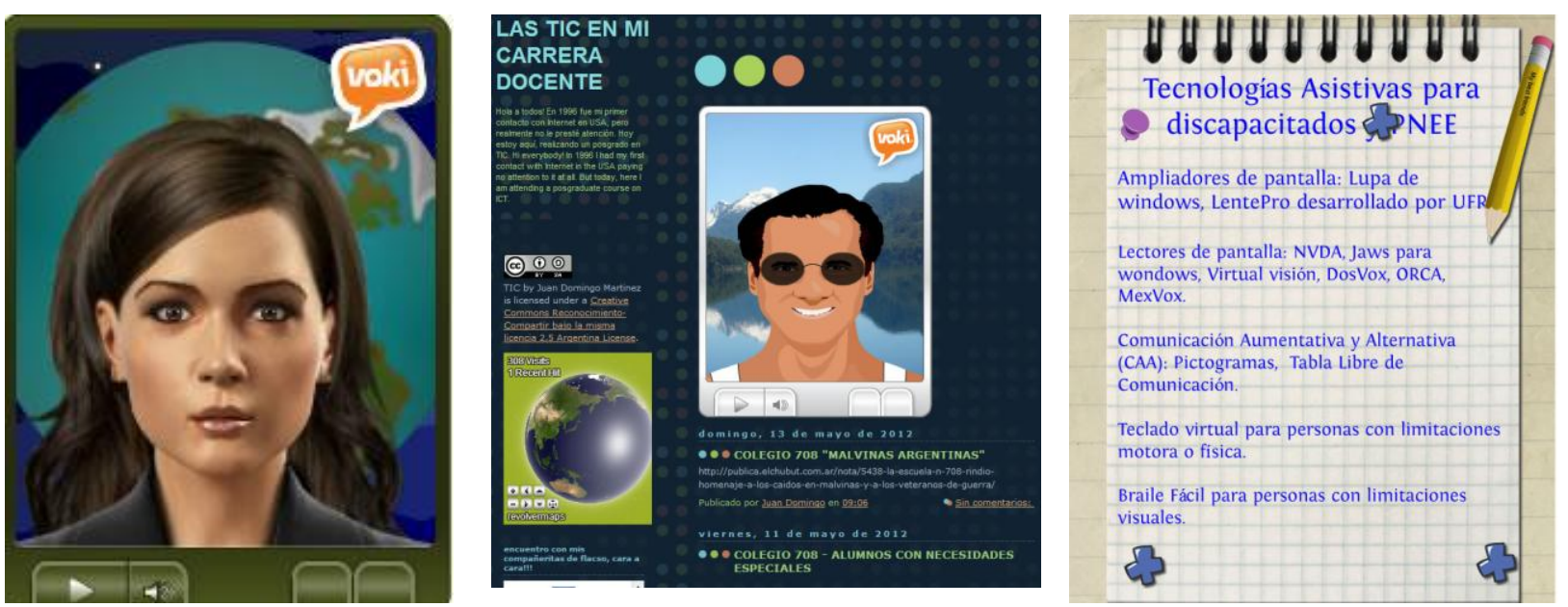

Figura 2. A conquista da fluência digital por educadores ibero-americanos: avatar, blog e glog (Banner virtual).

O processo de acompanhamento e de avaliação do curso não estaria completo sem que a possibilidade de conquista do poder da palavra fosse garantida também aos principais atores dessa formação: os educadores. Ao longo de todos os módulos, as estratégias de comunicação e de mediação operaram com interfaces de escuta, instrumentos que, ao mesmo tempo em que possibilitam acompanhar a construção da fluência digital na perspectiva da Educação Inclusiva, passam a fornecer dados para avaliação do módulo. Esse cuidadoso movimento permite analisar a adequação das atividades e dos materiais disponibilizados, com o fim de apoiar a sua realização e, principalmente, as percepções dos educadores quanto à temática proposta e às possibilidades de projetar práticas educacionais inclusivas. Os registros nos portfólios, 
nos diários de bordo, nas mensagens eletrônicas, nas postagens nos fóruns constituem o corpus de análise para que a equipe de coordenação possa obter significativas informações que qualificam as próximas edições do curso.

A esse movimento sistematizado e contínuo de acompanhamento e de avaliação de cada módulo do curso, soma-se uma avaliação, essa de caráter mais global, realizada ao final da formação. Por meio de um formulário online, é realizada uma consulta ao professor, para avaliar o serviço educacional ofertado, para caracterizar o grupo de educadores capacitados, para levantar as percepções quanto à pertinência do conteúdo, escolha metodológica, qualidade do material impresso e digital, entre tantos outros aspectos. $\mathrm{O}$ instrumento de consulta aos professores cursistas é composto de questões objetivas, mas a maioria é de caráter descritivo e reflexivo, focalizando a interação e as aprendizagens dos participantes no desenvolvimento da formação. A análise dos dados coletados por meio dessa avaliação global permite que os objetivos estabelecidos sejam validados, impulsionando a melhoria das edições subsequentes do curso.

Entre tantos aspectos abordados na avaliação do curso, os professores foram questionados sobre qual ou quais dos seis módulos trabalhados ao longo da formação mais despertaram sua atenção. A grande maioria dos professores cursistas destacou a relevância de mais de um módulo, o que atesta a satisfação do educador com a proposta curricular ofertada. Da mesma forma como ocorreu nas demais edições do curso, os professores cursistas destacaram as temáticas debatidas nos módulos de Recursos de Internet Acessíveis (Módulo 3), Acessibilidade à Web (Módulo 4) e Objetos de Aprendizagem Acessíveis (Módulo 5).

\section{Gráfico 2. Módulos destacados pelos educadores ibero-americanos.}

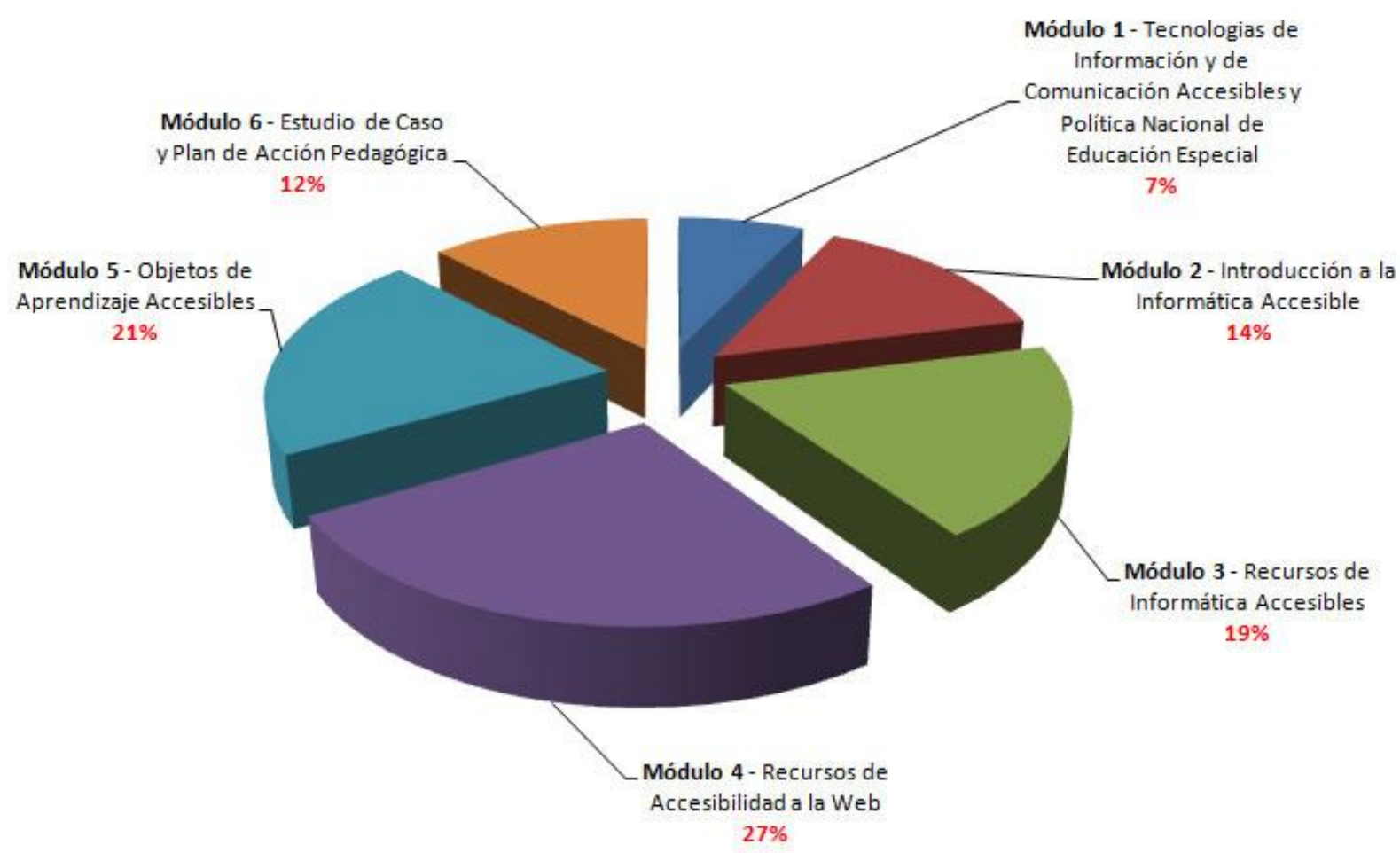

Dentre esses três módulos, os educadores apontaram para a relevância do módulo de Acessibilidade à Web, o que pode ser explicado pela contemporaneidade da temática e pela importância que a mesma assume em um contexto sociocultural e econômico fortemente apoiado nas ferramentas da Internet (Gráfico 2). Reafirma-se a 
premissa de que a construção de uma sociedade inclusiva passa pela acessibilização de todos os seus cenários, inclusive o digital.

Nesse processo de avaliação do curso, são encaminhadas questões para analisar aspectos relativos à estrutura e à metodologia do curso, à qualidade da interação dos formadores e dos tutores, ao processo de avaliação da formação docente. Nesse sentido, questionamentos como - Qual a sua opinião sobre as leituras propostas nos módulos do curso?; Qual a sua opinião sobre o material disponibilizado pelo curso? Qual a sua opinião sobre os vídeos e as palestras disponibilizadas? - têm como objetivo ouvir o educador em formação, pois é por meio desse diálogo que a coautoria e a busca permanente pela qualificação do processo se efetivam. Esses são aspectos centrais para que se possa avaliar a qualidade do serviço educacional ofertado. Para tal análise, os critérios utilizados na escuta buscam mapear as percepções dos professores: a positividade do compartilhar, a força do aprender a aprender, o sentido de pertencimento, a expressão da responsabilidade e da autoconfiança.

La organización del curso en su estructura permite involucrar al estudiante paulatina y pausadamente posibilitando el aumento del grado de dificultad, pero simultáneamente evidenciando en el proceso, poniendo en situación lo que hace un maestro desde su labor, lo que obliga a la organización, uso y manejo de nuevas herramientas, posibilitar la búsqueda de otros elementos de apoyo. (Professora Edicão 2011/2)

A positividade do compartilhar é um dos aspectos que pode ser seguramente percebido nesse processo de escutar o professor cursista. O sentido do compartilhar é proporcionado pelas trocas, tanto de conhecimento como de afeto. É por meio da construção desse significado de partilhar que o processo de aprendizagem na modalidade a distância é desencadeado, em especial pela possibilidade de minimizar a distância e a ausência física do colega e do professor.

iExcelente! Mis compañeros siempre estuvieron atentos a brindar recomendaciones y durante los chat. La dinámica siempre fue muy activa. Brindaron recomendaciones y aportes muy valiosos. (Professora Edição 2011/2)

A rede de contatos que a participação no curso potencializa é um dos aspectos de maior significado para a construção de um coletivo inteligente que não se dissolve com o encerramento do curso. Na medida em que o grupo passa a se perceber como um inteligente coletivo, o alicerce para edificar processos de aprendizagem pode ser concretizado. Muitas vezes, a angústia sentida pelo professor - pois se percebe solitário e isolado em sua instituição educativa - passa a ser enfrentada quando se institui um processo de construção coletivo de respostas, tecidas no encontro de educadores que vivenciam o mesmo desafio de concretizar a inclusão escolar. É na riqueza do encontro com a diferença que a positividade do compartilhar revela sua importância, um importante movimento instituído pelo curso.

Los puntos fuertes del curso, desde mi punto de vista, son: (1) Facilita la interacción con los profesores especialistas en el tema en tiempo real. (2) Permite más tiempo y flexibilidad, pues permite estar desde la comodidad de mi casa y estudiar. (3) Hace posible llevar a cabo mi propio ritmo de aprendizaje, elegir mi horario de trabajo. (4) Brinda la oportunidad de aprender de todos (profesores-estudiantes). (5) Reduce los gastos y costos de traslados, alimentación, materiales y otros comparándolo con un curso presencial. (Professora - Edição 2011/2) 
As palavras da professora cursista revelam "a cola" que une os educadores no desenrolar de todos os módulos do curso, "El curso realmente cumple con sus objetivos, va mucho más allá de la teoría y nos enfrenta directamente a la realidad de los diferentes entornos y posibilidades para adecuarlos a las necesidades específicas de nuestros estudiantes" (Professora - Edição 2011/2). É sobre essa percepção de um objetivo comum a ser atingido que a ação metodológica do curso alicerça sua ação. Ao enfatizar a necessidade de fazer a práxis e a teoria dialogarem, que efetiva-se a construção de novos saberes técnicos e teóricos e o desenvolvimento de habilidades cognitivas para apoiar a construção de práticas educativas inclusivas. Ao escutar o professor cursista sobre a ação metodológica do curso, foi possível perceber a adequação da proposta para o desenvolvimento profissional e intelectual dos educadores em formação. A reflexão da professora cursista, "sí, pues he mejorado mi percepción sobre las adecuaciones que deba realizar para garantizar el aprendizaje y la integración de todos mis estudiantes, así como también me ha ayudado a tener idea sobre algunas herramientas que puedo poder en práctica" (Professora - Edição 2011/2), reafirmamos a opção metodológica desenhada para a formação e que circunscrevem a complementariedade das ações pedagógicas expressas no explorar, experienciar, relatar e refletir. É importante para a equipe de coordenação pedagógica ver reconhecida e valorizada essa opção metodológica pelos educadores.

A construção da diferença como um valor pode ser reconhecida nas percepções dos professores ao refletirem sobre suas aprendizagens, ao analisarem suas expectativas iniciais em relação ao curso e como essas se confirmaram, ou não, ao final do mesmo. São relatos de aprendizagem de profissionais que evidenciam a expressão da responsabilidade e da autoconfiança necessárias para a concretização da Educação Inclusiva: "Todos y cada uno de los módulos que hemos trabajado durante el período que ha durado el curso han ayudado en lo pertinente a la construcción de unas mejores prácticas pedagógicas inclusivas, y no solo lo digo por mis estudiantes, sino también por mi ahora me siento incluido, o al menos en gran manera menos excluido; es algo recíproco. En mi caso, es lo que todos necesitamos siempre" (Professora - Edição 2011/2).

\section{Conclusões:}

O Curso de Formação de Educadores em Tecnologia de Informação e de Comunicação Acessíveis projetou um ergonomia cognitiva, pois mais do que projetar tempos e espaços para mediar atividades pedagógicas, colocou o foco de sua intervenção na problematização dos processos socioculturais que afetam a interação entre sujeitos e desses com a variedade de recursos tecnológicos que a sociedade contemporânea disponibiliza.

Ao projetar essa ergonomia cogntiva fomos fortemente acompanhados pelo pensar revolucionários de educadores como Vygotsky, Freinet, Freire, entre tantos outros... Pois, assim como para eles, nosso maior objetivo com a organização desse tempo e espaço de formação de educadores era a abertura de novas possibilidades de ajustar o cenário sociocultural de escolas de diferentes municípios brasileiros às especificidades da diversidade humana. Ao modificar o cenários educacional desejamos edificar projetos de vida para todos os marcados pela face negativa da deficiência. 
De todos os conceitos que discutimos ao longo do processo de formação de educadores, o que me melhor desenha a possibilidade de estruturar e de instituir relações mais positivas e produtivas com a diversidade humana é o construído por Paulo Freire (1992), o inédito-viável. A perspectiva do inédito-viável está relacionada à compreensão da história de vida de cada sujeito como uma possibilidade, um olhar construído na posição utópica que se opõe à visão fatalista da realidade e das especificidades humanas. O inédito-viável é o conceito que alicerça a proposta da superação que encerra em si, no ato de sonhar coletivamente, o movimento transformador. As reflexões dos educadores que caminharam ao lado da equipe de coordenação pedagógica e tutoria apontam rumo aos primeiros movimentos para a concretização desse importante e edificante conceito freiriano: "Más que ayudar la construcción de prácticas pedagógicas inclusivas, diría que aporta procesos de formación para que el maestro construya esas prácticas, pues una cosa es con que se cuenta y otra es determinar a lo largo de un proceso los alcances y transformaciones" (Professora - Edição 2011/2).

No atual estágio da sociedade contemporânea, e pelo potencial que vislumbra futuramente, podemos afirmar com grande convicção que, sem o apoio das tecnologias digitais, não será possível efetivar a inclusão escolar de alunos com deficiência. A meta do curso de formação continuada de professores em Tecnologias Digitais Acessíveis se expressa no qualificar do professor para a fluência digital, visando a construção de uma nova forma de pensar, de estar e de agir no mundo do século XXI, instrumentalizando-o para o processo de inclusão dos alunos com deficiência, com o apoio imprescindível e fundamental das tecnologias da informação e comunicação. Por meio do potencial transformador dessa premissa, pretendemos afinar e estreitar a formação com professores ibero-americanos.

\section{Referências}

Freire, P. (1996) "Pedagogia da autonomia: saberes necessários à prática educativa". São Paulo: Paz e. Terra.

Freire, P. (1992) "A pedagogia da esperança: um encontro com a pedagogia do oprimido". RJ: Paz e Terra.

Santarosa, L. et al. (2011) "Tecnologías digitales accesibles". Porto Alegre: JSM Comunicações Ltda.

Santarosa, L. et al. (2010) "Tecnologias digitais acessíveis". Porto Alegre: JSM Comunicações Ltda.

Santarosa, L. (2004) "Ambientes de Aprendizagem Virtuais para Inclusão Digital de Pessoas com Necessidades Especiais". Projeto de Pesquisa. CNPQ (2004 - 2006).

Santarosa, L. (2007) "Ambientes de Aprendizagem Virtuais para Inclusão Digital de Pessoas com Necessidades Especiais. Projeto de Pesquisa". CNPQ (2007 - 2009).

Santarosa, L. (2009) "Ambientes de Aprendizagem Virtuais e Inclusão: mediação pelas áreas de desenvolvimento potencial de pessoas com necessidades educacionais especiais". Projeto de Pesquisa. CNPQ (2007 - 2009).

Santarosa, L. (2010) "Construção de Espaços Virtuais Inclusivos para atendimento à diversidade Humana". Projeto de Pesquisa. CNPQ (2010 - 2014). 